\section{A Evolução da Tiroxenemia Materna e o Feto}

M AIS uma vez o Prof. Dr. Nassim Iazigi ficaria feliz! É impossível esquecer a satisfação expressa em seu rosto ao ler o artigo de Ball e cols. (1), em 1989, quando, utilizando métodos mais sensíveis, demonstraram que a redução da tiroxina livre, com a evolução da gestação, era um fenômeno fisiológico real e não um artefato. O trabalho do Prof. Nassim, que originou sua tese de Livre docência intitulada "Evolução do índice de tiroxina livre na gravidez", fora defendido em 1976 (2). Na época, seus resultados não coincidiam com os registrados pela maioria dos trabalhos disponíveis, que mostravam valores de índice de tiroxina livre (ITL), diferentes de autor para autor, porém similares em grávidas e não grávidas. Ele postulara, em sua tese, que a progressiva e significativa baixa dos valores de ITL registrados resultasse de um descompasso relativo entre os incrementos da quantidade de TBG e dos hormônios tireoidianos circulantes por déficit primário destes. Escreveu ainda: "Aceita a correlação estreita entre o ITL e valores numéricos de hormônios tireoidianos seríamos levados a ter que considerar, como corolário necessário, a hipótese de um estado de hipotireoidismo. No entanto, a completa ausência de qualquer evidência clínica no decorrer de todo o período gestacional de sinais e sintomas atribuíveis a hipotireoidismo nos leva a afastar esta possibilidade. Cumpreme, pois, levantar outra hipótese que justifique os achados deste trabalho...". Ele, então, atribuiu à carência iódica relativa a responsabilidade por determinar um incremento de produção de T3 e conseqüente redução de T4. O descompasso entre níveis de T3 e T4 justificaria o achado de menores índices de tiroxina livre na evolução da gestação. Estudos seqüenciais realizados por ele, em mulheres grávidas submetidas a suplementação iódica, confirmaram suas conclusões.

Estudos posteriores de Glinoer e cols. (3), conduzidos em área de carência iódica moderada, também observaram que as concentrações de T4 e T3 não aumentavam como seria esperado pelo aumento de TBG e, em aproximadamente $1 / 3$ das gestantes, hipotiroxenemia relativa estava presente com maior concentração de TSH. A razão de T3/T4 estava aumentada, o que era consistente com a secreção preferencial de T3.

Numerosas publicações se seguiram desde então, indicando que as concentrações dos hormônios tireoidianos diminuem na gestação, mesmo em áreas suficientes em iodo. O estudo de Roti e cols. (4), em 1991, comparando 10 diferentes métodos de dosagem de T4 livre mostrou que apesar da variabilidade dos resultados, todos apontavam para a mesma direção, ou seja, os hormônios livres são sempre significativamente menores que os da mulher não grávida. Entretanto, as razões para estas alterações, na mulher saudável, e em área suficiente em iodo, permanecem não compreendidas completamente.

Nesta edição dos ABE\&M, o manuscrito de Sieiro Neto e cols. (5), um estudo longitudinal envolvendo um número expressivo de gestantes $(\mathrm{N}=587)$, conduzido em área teoricamente suficiente em iodo e com metodologia adequada, confirma que os hormônios livres estão em média

\section{editorial}

\author{
Léa Maria Zanini Maciel
}

Divisão de Endocrinologia, Departamento de Clínica Médica, Faculdade de Medicina de Ribeirão Preto da Universidade de São Paulo (FMRP-USP), Ribeirão Preto, SP. 
$18,2 \%$ mais baixos no $3^{\circ}$. trimestre em relação ao primeiro trimestre. Apontam ainda que 23, 68 e 127 gestantes, no $1^{\circ}$., 20. e $3^{\circ}$. trimestres, respectivamente, apresentaram valores elevados de TSH, sendo que os valores máximos obtidos foram de $7,89 \mu \mathrm{U} / \mathrm{ml} ; 6,43$ $\mu \mathrm{U} / \mathrm{ml}$ e $6,53 \mu \mathrm{U} / \mathrm{ml}$, nos respectivos trimestres. Estes dados são preocupantes, pois valores de TSH nesta faixa seguramente traduzem hipotireoidismo, $\mathrm{O}$ que é corroborado pelo fato de valores mais elevados de TSH terem sido mais prevalentes em grávidas com títulos positivos de anticorpos anti-peroxidase.

A importância de se definir a faixa de normalidade de gestantes e de se detectar hipotireoidismo ou hipotiroxenemia maternos foi ressaltada em estudo publicado no fascículo de abril de 2004 dos ABE\&M por Vieira e cols. (6), que obtiveram, mediante análise utilizando ensaio imunométrico padronizado no próprio laboratório, valor máximo de TSH, em gestantes normais, de $3,5 \mu \mathrm{U} / \mathrm{ml}$.

$\mathrm{Na}$ impossibilidade de uma análise estatística mais adequada dos resultados com metodologias diversas, a comparação de valores médios de T4 livre nos estudos citados resultou em valores diferentes para o T4 livre nas diferentes fases da gestação, e salienta a importância da padronização das faixas de normalidade que deve ser definida em cada laboratório.

A importância da definição de normalidade e do reconhecimento do hipotireoidismo ou da hipotiroxenemia maternos já foram salientados previamente nos estudos de Man e cols. (7) nos anos 70, quando se demonstrou que mulheres da área de Rhode Island nos Estados Unidos apresentavam hipotiroxenemia na gestação e seus filhos, com idades entre 4 e 7 anos, valores de QI de 5 a 6 pontos inferiores aos nascidos de mães eutireoidianas. Mais recentemente, estas observações foram reforçadas com os estudos de Haddow e cols. (8) e Pop e cols. $(9,10)$. Neste último estudo (10), os autores destacam que a correção da hipotiroxenemia materna, em qualquer momento da gestação, sempre resultará em benefícios para a criança.

Finalmente, considerando as repercussões funcionais determinadas pela hipotiroxenemia materna, decorrentes de deficiência de iodo ou de tireoidite auto-imune, investigações adicionais serão necessárias para definir mais precisamente quais as concentrações de T4 livre que poderão irreversivelmente prejudicar o desenvolvimento cerebral fetal.

\section{REFERÊNCIAS}

1. Ball R, Freedman DB, Holmes JC, Midgley JE, Sheehan CP. Low-normal concentrations of free thyroxin in serum in late pregnancy: physiological fact, not technical artefact. Clin Chem 1989;35:891-6.

2. Iazigi $\mathrm{N}$, Veríssimo JMT, Kieffer J, Riscalla $\mathrm{H}$, Janógio $\mathrm{O}$, Moreira AC, et al. Evolução do índice de tiroxina livre na gravidez. Rev Ass Med Brasil 1979;25:228-34.

3. Glinoer D, de Nayer P, Bourdoux P, Lemone M, Robyn C, van Steirteghem A, et al. Regulation of maternal thyroid during pregnancy. J Clin Endocrinol Metab 1990;71:276-87.

4. Roti E, Gardini E, Minelli R, Bianconi L, Flisi M. Thyroid function evaluation by different commercially available free thyroid hormone measurement kits in term pregnant women and their newborns. J Endocrinol Invest 1991;14:1-9.

5. Sieiro Neto L, Coeli CM, Micmacher E, Mamede SC, Nazar LO, Correa EK, et al. Estudo longitudinal do eixo hipófise-tireóide durante a gravidez. Arq Bras Endocrinol Metab 2004;48:493-8.

6. Vieira JG H, Kanashiro I, Tachibana T, Ghiringhello MT, Hauache OM, Maciel RMB. Definição de valores normais de tiroxina livre durante a gravidez. Arq Bras Endocrinol Metab 2004;48:305-9.

7. Man EB, Jones WS, Holden RH, Mellitis ED. Thyroid function in human pregnancy. VII. Retardation of progeny aged 7 years: relationship to maternal age and maternal function. Am J Obstet Gynecol 1971:905-16.

8. Haddow JE, Palomaki GE, Allan WC, Williams JR, Knight GJ, Gagnon J, et al. Maternal thyroid deficiency during pregnancy and subsequent neuropsychological development of the child. N Engl J Med 1999;19:341:549-55.

9. Pop VJ, Kuijpens JL, van Baar AL, Verkerk G, van Son $\mathrm{MM}$, de Vijlder JJ, et al. Low maternal free thyroxine concentrations during early pregnancy are associated with impaired psychomotor development in infancy. Clin Endocrinol (Oxf) 1999;50:149-55.

10. Pop VJ, Brouwers EP, Vader HL, Vulsma T, van Baar AL, de Vijlder JJ. Maternal hypothyroxinaemia during early pregnancy and subsequent child development: a 3year follow-up study. Clin Endocrinol (Oxf) 2003;59:282-8.

\section{Endereço para correspondência:}

Léa Maria Zanini Maciel

Faculdade de Medicina de Ribeirão Preto - USP

Av. Bandeirantes, 3900

14049-900 - Ribeirão Preto - SP

Fax: (016) 633-1144

e.mail: Imzmacie@fmrp.usp.br 